\title{
CITIZEN INFLUENCES ON STATE POLICY PRIORITIES: THE INTERPLAY OF PUBLIC OPINION AND INTEREST GROUPS
}

Saundra K. Schneider and William G. Jacoby

Michigan State University

August 2005

sks@msu.edu

jacoby@msu.edu

Prepared for delivery at the Annual Meetings of the

American Political Science Association.

Washington, DC, September 1-4, 2005. 
Political scientists generally believe that public opinion affects public policy within the American states. While such a connection may seem obvious, firm empirical evidence for the existence of this relationship has only been presented quite recently. Early studies of state policymaking emphasized economic factors as the predominant determinants of governmental activity (Dawson and Robinson 1963; Dye 1966; Sharkansky and Hofferbert 1969). Once variables like per capita income, gross state product, and employment levels were taken into account, political characteristics like party composition of state legislatures, gubernatorial partisanship, and political culture seemed to have no effect. These results were replicated a number of times and widely accepted by state politics scholars (Hofferbert 1974).

Of course, political scientists were extremely uncomfortable about the sizable body of empirical evidence that showed politics was irrelevant to governmental decision-making within the states. Therefore, research continued on this topic with dogged determination to show otherwise. The major breakthrough occurred with the pioneering work by Wright, Erikson, and McIver (1985). They used survey data, aggregated to the state level, in order to develop measures of citizen partisanship and ideology within each state. They provide compelling evidence that these measures are effective gauges of mass orientations, and, more important, they show that these aspects of public opinion have a strong influence on state policy liberalism. Indeed, once public opinion is taken into account, economic factors play only a secondary role as determinants of policy (Erikson, Wright, McIver 1989, 1993).

The primacy of public opinion was immediately and joyously accepted by political scientists, and it has become the new conventional wisdom within this field. Recent work has been aimed at extending and refining the Wright, et al. variables, as well as developing 
alternative measures of citizens' opinions at the state level (Berry, Ringquist, Fording, and Hanson 1998). Regardless of specific operationalizations, mass orientations have been shown to affect policy across a broad array of substantive areas (Wright, Erikson, and McIver 1987;

Erikson, Wright, and McIver 1993; Lowery, Gray, and Hager 1989; Burstein 2003; Gray, Lowery, Fellowes, and McAtee 2004).

We wholeheartedly agree that the recent work represents a highly significant step to understanding the state policymaking process. But, we also believe that further work is necessary in at least two directions. First, it is important to identify where and how public opinion impinges upon the policymaking process. Second, the specification of influences on policies must be expanded to incorporate another set of critical actors in the political process - interest groups. This paper constitutes a first step toward those objectives.

\section{MEASURING STATE POLICY}

A perusal of the literature reveals that there are three dominant approaches to measuring public policy within the states. Many researchers use program expenditures. Another set of scholars relies upon specific policy adoptions. A third group employs composite variables constructed from multiple indicators. We believe that all of these approaches are problematic, for different reasons.

\section{Previous Approaches}

First, let us consider the research that use policy expenditures as the dependent variable. Studies that take this approach generally focus on spending (usually adjusted by state population, or program recipients) within a single policy area (e.g., Barilleaux, Holbrook, and Langer 2002). This measurement strategy has a number of advantages: Spending data are readily available; expenditures are tangible indicators of governmental efforts; the dollar figures constitute 
continuous, interval-level measurement; and spending levels are immediately comparable across states and time. Probably for these reasons, program expenditures have been used to examine policymaking across a wide variety of specific areas, including welfare, health care, education, and environmental protection (Rom 1999; Lewis and Maruna 1999; Ringquist 1993).

Despite their ubiquity in the field, there is a serious drawback to the use of policy expenditures. Spending within any given policy area is invariably affected by state spending across other policies, which are not under immediate investigation. Unlike the federal government, the states have balanced budget requirements. Therefore, spending increases on one program are invariably offset by decreases in other programs, and vice versa (Garand 1985; Garand 1988; Garand and Hendrick 1991). Empirical analyses that use expenditures on a single program as the dependent variable fail to take this rather basic feature of state policymaking into account. This creates an omitted variable bias in the estimates provided by statistical models. And the severity of this bias is determined by governmental decisions with respect to other policies - those that are not included in the statistical analysis.

The second approach employs program enactments as the main indicator of governmental activity. This general tradition has encompassed several specific approaches. Some studies use innovation/diffusion models to examine the timing and sequence of state-level program adoptions (Walker 1969; Gray 1973; Eyestone 1977). Others employ event history models to predict when each state will take a concrete policy action (Berry and Berry 1990). Regardless of the specific methodology, the hallmark of this research tradition is a focus on discrete actions by state governmental decision-makers, rather than the degree/level of effort or the amount of resources expended toward the achievement of particular goals. 
The problem with program enactments is not really a matter of their validity as an indicator of policymaking; rather it involves their connection to public opinion. Stated simply, most citizens do not have the knowledge, interest, or expertise to exert a direct influence on the specific actions of governmental decision makers. The empirical evidence has repeatedly and conclusively demonstrated low levels of political sophistication throughout the American electorate (e.g., Zaller 1992). If that is the case, then it is difficult to specify how citizens' orientations would directly affect elite actions. We are not questioning the general correlation between state-level opinion and policy. However, given the cognitive limitations that exist within the mass public, we believe the relationship between opinion and program enactments to be spurious and due to the impact of public opinion on other elements of the policy process.

A third general approach is to use data reduction techniques such as factor analysis to summarize many different policy indicators simultaneously. Although their exact results differ somewhat, the studies in this tradition all demonstrate that there is a systematic, coherent framework underlying the ways that states address the myriad array of pressures confronting them. The early pioneering studies typically produced two separate dimensions of state policymaking (Sharkansky and Hofferbert 1969). More recent analyses have generated unidimensional representations of state policy liberalism (Klingman and Lammers 1984; Wright, Erikson, and McIver 1987). The strengths of this analytic strategy have been widely recognized and the resultant measures have been employed fairly frequently in the recent literature (Hill, Leighley, and Hinton-Anderson 1995; Lascher, Hagen, and Rochlin 1996).

There are some potentially serious problems in the multiple-indicator policy variables. For one thing, they typically incorporate an ad hoc array of governmental activities (e.g., program expenditures, legislative provisions, program adoptions, tax progressivity, etc.). Hence, 
they may confound several different aspects of the public policymaking process. Furthermore, the composite variables usually combine data from several time points, spanning periods from seven to fifteen years long. This is problematic because policy considerations almost certainly change over time. Any such temporal variability is lost when the data are combined into a single summary index. For these reasons, it is impossible to say exactly which, if any, specific aspects of the policy process are represented in the final summary measures that are developed in the composite policy studies.

\section{An Alternative Approach: Policy Priorities}

Because of the problems in the previous work, we believe that it is necessary to develop an alternative approach for assessing the impact of public opinion on state policymaking. Specifically, we argue that the appropriate dependent variable for this purpose is state policy

priorities - the relative allocation of governmental resources across all of the program areas within which states are active. Policy priorities are a clear manifestation of the institutional commitments of state governments (Jacoby and Schneider 2001). They operationalize the "governmental decision agendas" within the respective states (Kingdon 1984); that is, the relative salience that state-level public officials accord to various social and political issues (Baumgartner and Jones 1993).

Policy priorities occupy a central position in the state decision-making process. They are the prime target of those who would influence government (Raimondo 1996; Winters 1999). In effect, priorities serve as a "bridge" between public demands and governmental services. The notion of relative policy priorities is fully consistent with the idea of public opinion as a "blunt instrument" which affects the general direction of state activity without becoming involved in 
specific programmatic details. Therefore, we believe this is the appropriate place to look for the impact of citizens' attitudes on public policy in the states.

The problem, of course, is to measure policy priorities. In doing so, it is useful to focus on program expenditures. But, for the reasons discussed earlier, spending within a single issue area is problematic. Many researchers agree that expenditures alone cannot be used to measure policy outputs and/or impacts (Hofferbert 1974; Walker 1969; Hanson 1984; Erikson, Wright, and McIver 1989). However, there is a scholarly consensus that spending levels across areas provide the clearest, most unambiguous, indicators of governmental commitments to address various societal problems (Ringquist and Garand 1999; Raimondo 1996; Garand and Hendrick 1991). But, how can this be done within a single variable?

The raw data for our measure of policy priorities will consist of yearly state general expenditures in ten program areas: Education, welfare, hospitals, health, highways, policy, corrections, parks, natural resources, and government administration. These program areas represent virtually the full range of substantive concerns that typically confront state governments. We are interested in the states' relative priorities across the different policy areas; that is, how the states divide up their available pools of resources. Our analysis does not seek to explain how much states spend on the different programs. Therefore, the yearly policy-specific values within each state are expressed as proportions of the total policy expenditures for that state in that year across all ten categories.

The policy priorities measure will be based upon a geometric representation, often called a "spatial proximity model," of the state spending data. The basic idea behind this model is very simple. The fifty states and the ten policy areas are shown as two sets of points located along a common continuum. The relative positions of the points are determined by the empirical 
expenditure values. Specifically, states $I$ 's spending on policy $A$ is inversely proportional to the distance between the point representing $I$ and the point representing $A$ : As spending increases, this distance gets smaller and vice versa. Thus, state points will tend to be located close to the points representing policies for which their relative spending levels are high and far from the points representing policies where their relative spending levels are low.

The overall spatial proximity model for the state spending data will consist of two distinct set of points for each year included in the analysis: One set of fifty state points and a second set of ten policy points. States with similar spending profiles will have points that are located close to each other along the dimension; states with markedly different spending priorities will have larger distances between their points. A similar distance rule applies to the policies themselves: Policies that receive similar proportional allocations in state budgets will be represented by points that fall close to each other along the dimension. Policies that exhibit contrasting spending patterns (i.e., high relative expenditures in one policy area coincide with small expenditures in another) will be shown as widely-separated points.

Many specific procedures — usually called "unfolding techniques"— have been developed to estimate the parameters of the spatial proximity model (e.g., Cox and Cox 2000). Our analysis uses a metric, least-squares unfolding method developed by Keith Poole (1984). The overall approach is called "unfolding" because, according to the geometry of the model, a state's profile of spending values can be obtained by "folding" the unidimensional continuum at the location of the state's point (Coombs 1964). The scaling task is the opposite of this process: We begin with the folded versions of the dimension (i.e., the input data values) and seek to "unfold" them simultaneously across all states, in order to estimate the dimension itself (i.e., the relative positions of the state and policy points). The method is "metric" because it assumes that 
the input data are measured at the interval level or higher (many unfolding techniques only assume ordinal or even nominal measurement levels). The method is "least-squares" because its immediate analytic objective is to find the set of state and policy point locations such that the squared errors between distances and data values are minimized.

\section{Empirical Estimates of State Policy Priorities}

The spatial proximity model could be estimated for any years in which the relevant spending data are available. However, because of data limitations for some of the other variables in our analysis, we only use policy priorities for the years 1998, 1999, and 2000. ${ }^{1}$ During this time period, the unidimensional spatial proximity model provides an excellent representation of the state-level spending data. The squared correlation between the scaled interpoint distances (i.e., between state and policy points) and the input expenditure figures is extremely high at 0.958. Hence, the scaled array of state and policy points mirrors the empirical data almost perfectly.

Figures 1 and 2 provide graphical representations of the scaled point locations. ${ }^{2}$ Figure 1 shows a dot plot of the policy points, while Figure 2 shows a similar display for the state points. The point locations exhibit virtually no movement whatsoever during this time period. Therefore, the graphical displays only show the mean locations (across the three years) for each policy and state point, respectively. The information in the dot plots is easily interpreted (Jacoby 1997). To find the scale value for any particular policy (or state), one merely locates the policy (or state) along the vertical axis, scans horizontally along the dotted line to the point location within the display, and then scans vertically down to the scale value located along the horizontal axis. In this manner, the two dot plots completely summarize all of the information provided by the scaling analysis. 
Examination of the dot plot in Figure 1 shows that most of the ten policy areas fall within two strongly contrasting groups: The scaled points near the left end of the continuum are designed to deal with the needs and demands of specific state constituencies, ranging from the neediest strata (the poor, who benefit from welfare and health care) to distinctive occupational groups (e.g., police officers and governmental employees who benefit from law enforcement and administrative expenditures, respectively). The points located at the other side of the continuum represent policies that ostensibly benefit all of society rather than narrowly-defined segments of the population - education, highways, and natural resources. Thus, the empirical evidence shows that state policy priorities range along a dimension from particularized benefits to collective goods (Jacoby and Schneider 2001).

Note that there is one potentially anomalous placement: The point representing spending on parks is located among particularized benefits rather than collective goods. We have no ready explanation for this. But, we do not believe that it compromises the basic bipolar nature of the priorities continuum. It is simply the case that states with higher levels of spending for parks and recreational services also place greater emphasis on constituency-specific benefits.

Figure 2 shows the dot plot for the states. Note that the state points are located along the same dimension as the policy points. Therefore, the points that fall near the right side of the plot represent states that spend more on education, highways, and natural resources - in other words, collective goods. The points closer to the left side of the plot are states that devote larger portions of their budgets to particularized benefits (e.g., welfare, health care, law enforcement, etc.). Points near the middle of the plotting region correspond to states that balance their spending more evenly across the two contrasting sets of policy areas. Thus, there is definitely variability in state policy priorities. And, the observed differences conform to a systematic, 
readily interpretable contrast between two types of governmental commitments: States that spend more on particularized benefits inevitably spend less on collective goods, and vice versa. The main task for the remainder of the paper is to explain this observed variability in state policy priorities. Specifically, we will try to determine the role of state public opinion as an influence on patterns of state program expenditures.

\section{INITIAL RESULTS: BIVARIATE RELATIONSHIPS}

The first step in assessing the impact of citizens' attitudes on policy priorities is to operationalize public opinion. Within the field of state politics, researchers have taken several different approaches over the years. These can be roughly divided into three sets: political culture/regional measures, survey-based measures, and estimates obtained from elections and office-holder characteristics. Let us consider briefly the bivariate relationships between each of these public opinion measures and the state policy priorities variable.

\section{Political Culture and Region}

Scholarly conceptions of state political culture have been heavily influenced by the work of Daniel Elazar $(1966,1984)$. He divided states into three groups based upon the predominant ethnic and religious values of the earliest settlers within each state's borders. In moralist states, government plays an active role in promoting the common good. Individualist states emphasize the marketplace with government policies as a means of facilitating individual rewards. Traditionalist states have relatively elitist cultures aimed at maintaining existing social and economic strata. Sharkansky (1967) later refined Elazar's original categorical distinctions. He argues that cultural differences form a continuum ranging from moralist to traditionalist orientations, with individualistic cultures falling in between the two extremes. 
Figures 3 and 4 show the empirical relationships between the two related measures of political culture and the policy priorities variable. Consider the boxplots in Figure 3. Individualistic states show extremely wide variation in policy priorities; the scores assigned to these states cover almost the full range of the policy priorities scale. The range of priority scores for traditionalist states falls almost completely within that for moralistic states. Both of the latter two categories overlap the upper half of the distribution for individualistic states. Thus, Elazar's political culture categories do not differentiate the states according to their policy priorities.

Figure 4 shows the scatterplot of state policy priorities versus Sharkansky's political culture scores, along with an OLS regression line fitted to the data. Stated simply, there is no relationship between the two variables. The cloud of points in the plot shows no discernible pattern, and the slope of the regression line is almost perfectly flat.

In contrast to subjective and possibly time-bound conceptions of political culture, other analysts simply use regional classifications as a crude indicator of differences in predominant opinions within states (Erikson, Wright, and McIver 1993). Therefore, Figure 5 shows the distribution of state policy priorities within the four regions of the United States. One feature is immediately apparent. Northeastern states fall near the lower end of the priorities scale, indicating that they place a greater emphasis on particularized benefits than do the other states. Beyond this, however, there are no clear patterns of regional distinctiveness in policy priorities.

Taken together, these results show that state political culture, at least as it is conceptualized by Elazar and his followers, has no impact on policy priorities. Nor do regional differences provide much leverage beyond the general distinctiveness of Northeastern states. It is important to emphasize that region and culture are more or less permanent characteristics of the states. Therefore, by definition, they cannot be used to account for any temporal variability in 
state policy priorities. Admittedly, the states do not change much during the short time period covered by our investigation. But, this problem still highlights the fact we need more direct measures of public opinion. And, it is to those that we now turn.

\section{Survey-Based Measures}

The recent, rapid expansion of the survey research industry has enabled more direct measurement of citizen orientations within the states. The most prominent work in this area has been carried out by Wright, Erikson, and McIver (1985); also see Erikson, Wright, and McIver (1993). They use information drawn from state-level CBS News/New York Times surveys to obtain yearly readings of mass partisanship and ideology within the states. For each year, within each state, the former is defined as the proportion of survey respondents who identify themselves as Republicans minus the proportion that call themselves Democrats. ${ }^{3}$ Similarly, ideology is defined as the proportion who call themselves conservative minus the proportion that call themselves liberal.

Figures 6 and 7 show the scatterplots of policy priorities against mass partisanship and ideology, respectively. The scatterplots also include OLS regression lines fitted to the respective bivariate datasets. The evidence shows that these variables are definitely related to each other in a direction that corresponds to reasonable prior expectations. States with more Republican identifiers and/or conservative electorates exhibit higher priority scores, meaning that they place relatively a strong emphasis on collective goods. In contrast, states with more Democratic identifiers and/or more liberal citizens show low policy priority scores, indicating that they focus more directly on benefits for particular groups. This is exactly what we would expect given the two parties' platforms and the issue stands associated with liberal and conservative ideologies. 
Thus, in contrast to the results for political culture, these displays confirm that public opinion is clearly related to the allocation of governmental expenditures within the states.

\section{A Measure Based Upon Officeholder Characteristics}

Erikson et al. measure citizen ideology using individual respondents' self descriptions. However, this may be problematic because there is a massive amount of evidence suggesting that sizable segments of the mass public do not deal very effectively with abstract, ideological terms, like "liberal" and "conservative" (Converse 1964; Jacoby 1995). If that is the case, then it is not entirely clear what ideological identifications are really measuring. And, for that reason, we turn to a second measure of state-level citizen ideology. Berry, Ringquist, Fording, and Hanson (1998) use interest group ratings of, and popular votes received by, congressional incumbents and challengers, aggregated within each state and year. Their variable is coded so that larger values correspond to more conservative state electorates. ${ }^{4}$

Figure 8 shows the relationship between the Berry et al. ideology measure and the policy priorities scale. Just as with the Wright et al. measures, there is a clear relationship between the two variables. States with liberal electorates emphasize particularized benefits, while conservative states focus on collective goods. What is distinctive here is that this relationship continues to exist with a behaviorally-based ideology measure. While the results are consistent, we believe that this represents a different phenomenon than the identification-based measure used by Erikson et al.

Erikson et al. and Berry et al. make an important contribution by providing relatively direct measures of state public opinion. When operationalized in those ways, public opinion is clearly related to state policy priorities. However, the wide spread of points around the regression lines in the scatterplots for these variables also shows that the relationships are far 
from deterministic in nature. The correlation (Pearson's r) between state partisanship and policy priorities is only 0.413 , while that for the Erikson et al. mass ideology measure is 0.458 . The correlation for the Berry et al. citizen ideology variable is somewhat larger, but still only moderate in size, at 0.570 . Thus, we argue that it is important to consider additional factors in order to obtain a more complete depiction of the influences on state policy priorities.

\section{THE ROLE OF INTEREST GROUPS}

Along with public opinion, interest groups are universally believed to be an influence on governmental decision-making. They are central figures in modern empirical democratic theory. For example, pluralist conceptions of power maintain that politics involves ongoing competition among groups (Truman 1951; Dahl 1961). Modern societies comprise many distinct interests, and the resultant existence of multiple groups guarantees the need for bargaining, accommodation, and compromise in the policymaking process. From this relatively benevolent perspective, interest groups serve as communication channels and focal points for distinctive points of view within the political system.

A less positive interpretation holds that interest groups subvert the policy process to their own ends. Critical theories of democratic elitism contend that groups promote existing inequalities and stifle the preferences of ordinary citizens (Schattschneider 1960). A related perspective holds that powerful groups control the governmental agenda, thereby preventing important issues from ever coming up for consideration (Bachrach and Baratz 1962). The role of interest groups is particularly insidious because "iron triangles" develop into relatively permanent linkages between private concerns and governmental decision makers (Lowi 1964). Once again, the needs and interests of the general public are simply pushed aside in the face of the pressure groups and lobbyists who are more directly and constantly involved in the process. 
Regardless whether one takes a positive or negative new of interest groups, it is simply impossible to deny their ubiquity in public policymaking. Given this fact, it is surprising that interest groups have seldom been incorporated into analyses of public opinion and the policy process. This is a serious deficiency because the resultant underspecified models probably distort the effects of the hypothesized influences on governmental activity. Specifically, the measures of public opinion that are included in the models may be picking up some of the effects that should be attributed to the interest groups that are omitted from the same models.

At least part of the reason for this problem stems from the lack of data pertaining to statelevel interest groups. However, this situation has been addressed by Virginia Gray, David Lowery, and their colleagues (2004). These researchers have collected information on the interest group communities within the states. Their work shows that state lobbying environments affect a number of important phenomena, including the sizes of state governments and intra-state economic growth. In earlier work, we have shown that interest group concentrations affected state policy priorities in the early 1990s (Jacoby and Schneider 2001). Thus, there is ample empirical evidence to back up beliefs about the importance of interest groups.

For present purposes, we use some additional data recently collected and made available to us by Gray and Lowery. They identify organized groups registered to lobby within each state and categorize those groups into twenty-six categories based upon the substantive focus of their lobbying efforts. We focus on the subsets of those categories that pertain to particularized benefits and collective goods. The former include civil rights, government employees, health care, insurance, the legal profession, police and fire protection, welfare, and women's groups. Collective goods include agriculture, communications, education, environmental groups, good government groups, natural resources, transportation, and utilities. We use this information to 
create two variables: The proportion of registered lobbying groups within a state devoted to particularized and collective goods, respectively. This information is available on a yearly basis for 1997 through 1999; however, the states' values do not change at all within this time period.

We do recognize that the proportion of groups active on specific kinds of issues does not translate directly into political power. Nevertheless, larger numbers of groups within a substantive area will increase the opportunity for the articulation of those interests, and, hence, the degree to which governmental decision-makers are exposed to particular points of view. Therefore, we believe that these variables can function as reasonable indicators of interest group pressure on the policymaking process - the degree to which they are trying to move the states toward one of the two ends of the policy priorities continuum.

Figure 9 and 10 show the relationship between the two interest group variables and state policy priorities. The results show that the concentration of interest groups in a particular substantive area corresponds to larger governmental expenditures on the corresponding policies. The connection is stronger for collective goods than for particularized benefits: The bivariate correlations are 0.503 and -0.243 , respectively. States with larger proportions of their interest group population focused on collective goods also devote greater portions of their overall resources to those kinds of policies. A similar relationship holds for groups and policies in the particularized benefits area. This provides clear preliminary evidence that interest groups should, in fact, be incorporated into any model representing the determinants of state policy priorities.

\section{COMBINED EFFECTS OF PUBLIC OPINION AND INTEREST GROUPS}

The discussion so far has looked at the effects of separate variables on state policy priorities. In order to obtain a relatively accurate assessment of their influence, however, it is necessary to combine these variables into a single, more comprehensive, model. Specifically, we 
will use the policy priorities variable as the dependent variable, expressed as a function of measures representing three types of influences. Two variables represent public opinion: Wright, Erikson, and McIver's mass partisanship variable and Berry et al.'s citizen ideology indicator. ${ }^{5}$ Second, interest groups are represented by the two variables discussed earlier: The percentages of groups within each state devoted to particularized benefits and collective goods, respectively. Third, region is operationalized as dummy variables representing northeastern, southern, and western states. Midwestern states are omitted as the reference category. We include the latter variables primarily as controls to pick up the residual effects of socioeconomic differences that exist across the states.

The data constitute measures on all fifty states across a three year-period. The dependent variable values cover 1998 through 2000; the independent variables are lagged one year to provide an unambiguous causal direction for their influences. Given the cross-sectional, timeseries nature of the dataset, the model's parameters are estimated using panel-corrected standard errors and allowing for first-order autoregressive patterns in the residuals.

\section{Direct Influences on State Policy Priorities}

Table 1 shows the Prais-Winston estimates from the regression analysis. The overall model fit is quite good, with an $\mathrm{R}^{2}$ of 0.776 . Notice also that the autoregression parameter is very large $(r h o=0.679)$ indicating that there is a systematic linear pattern among the disturbances. This is not surprising at all, given the incremental nature of state policymaking. Policy priorities do not change very much over time. So, the inertial pattern that apparently exists among the residuals is to be expected.

Turning to the separate independent variables, public opinion does influence policy priorities, but the magnitude of its effect is rather tepid at best. The coefficient for mass 
partisanship is barely significant at the 0.05 level with a directional test. But, using the same decision criterion for the hypothesis test, the coefficient for citizen ideology does not achieve statistical significance. Thus, Democratic electorates move a state toward more spending on particularized benefits while a Republican citizenry leans in the other direction, toward spending on collective goods. Citizens' liberal-conservative orientations have no such effect.

In contrast to the public opinion variables, the two interest group measures are both statistically significant in the expected directions. Exactly as anticipated, a higher concentration of lobbyists working for collective goods moves the allocation of state resources toward those kinds of policies. And, of course, a larger percentage of lobbying groups aimed at particularized benefits has the opposite effect— leading states to spend more money on policies like welfare, health care, and law enforcement (i.e., those that fall on the particularized benefits side of the policy priorities continuum). Comparing these two types of groups, the impact of collective goods lobbying is much more pronounced than that for particularized benefits: The absolute value of the coefficient for the former is more than four times larger than that for the latter, and the difference is statistically significant.

Finally, the three dummy variables for region all have negative, statistically significant coefficients. This shows that midwestern states (i.e., those in the omitted reference category) place a higher priority on collective goods than do states in the rest of the nation. The difference is particularly pronounced when it comes to northeastern states: The coefficient for the latter is more than five times larger than that for southern states and over four times larger than that for western states. Clearly, particularized benefits are a more important governmental priority in the northeast than in anyplace else across the country. 


\section{The Indirect Effect of Public Opinion}

The results so far suggest that interest groups overwhelm public opinion in the determination of state policy commitments. However, we suspect that such a conclusion might be a bit premature. A number of theories assert that interest groups provide voice and channels of access for citizens within society. For example, the social capital literature shows that participation in formal organizations enhances democratic activity within a political system (Putnam 1995, 2000). Another line of research focuses on increasing public involvement in issues, much of which is channeled through policy-oriented groups (Heclo 1978). Finally, the general theory of pluralism holds that interest groups are the main linkages between citizens and government (Truman 1959, Dahl 1963). According to all of these theoretical perspectives, public opinion may influence the group environment within a state, and thereby exert an indirect effect on policy priorities.

In order to test this possibility, we regress the percentages of interest groups within a state devoted to collective goods and to particularized benefits on the public opinion and region variables used above. The results are presented Table 2. Once again, we use Prais-Winsten estimates with panel-correlated standard errors because the yearly information on the common pool of states yields nonindependent observations within the dataset.

The two separate regression models both fit the data very well, and, just as before, there is clear evidence of temporal patterning in the disturbances. But, for present purposes the most important results in the table involve the coefficients on the public opinion variables. In the equation for collective goods, citizen ideology and partisanship both have significant effects. The direction of influence is consistent in each case, with more conservative and Republican states corresponding to higher percentages of groups devoted to collective goods. In contrast, the 
coefficients for these same variables in the particularized benefits equation are very small and not significantly different from zero. This suggests that mass orientations have no discernible effect on the formation of groups that address narrow concerns within their respective states.

Finally, interest group concentrations vary quite a bit across regions. However, geographic differences are not the main focus of this analysis, and the current data provide no explanation for why they exist in the first place. Therefore, we merely present the results without further comment.

Our analysis shows that, while interest groups circumscribe the impact of public opinion on policy priorities they certainly do not eliminate it. In fact, the empirical results explicate our understanding of mass influence by showing that public opinion has the greatest effect when it is channeled through groups. So, for example, electorate partisanship has a significant impact. This is reasonable because political parties are the main points of reference connecting citizens and the political system (Campbell, Converse, Miller, Stokes 1960). In contrast, citizen ideology involves more abstract and nebulous concepts; therefore, it is much more difficult for citizens to make the appropriate connections (Converse 1964; Jacoby 2002). Viewed in this light, the absence of a direct ideological influence on policy priorities is understandable.

At the same time, both elements of public opinion, ideology and partisanship, affect the formation of groups in the first place. Interestingly, this relationship only exists among groups aimed at broad policy objectives. Thus, public influence is oriented toward organizations working on issues that have far-reaching and highly visible consequences, such as education and highways. Particularized benefits, by definition, channel the rewards of government toward fairly narrow targets and these seem to be largely outside the domain of public concern. 


\section{CONCLUSIONS}

In this paper we have attempted to refine the scholarly understanding of the role of public opinion in state politics. We believe our analysis makes two specific contributions. First, we have identified a likely access point where external actors - public opinion and interest groups - gain entry into the governmental system. Policy priorities serve this function very nicely because they represent the relative allocation of resources, but bypass specific details of governmental programs and administration. This is precisely where we would expect citizens' voices to have the loudest resonance, and it is certainly a point in the policymaking process that self-motivated groups would try to influence. After all, nothing can be done unless the resources are provided to address specific conditions and social problems.

The second contribution is to embed public opinion within a broader model of policymaking than has previously been employed in the state politics literature. Recent empirical analyses of the relationship between public opinion and state policy have largely ignored the presence and possible effects of interest groups (Gray et al. 2004 constitute a prominent exception to this generalization). This broad omission of a class of explanatory factors is particularly surprising given that interest groups are a central feature in all modern theories of political power.

In conclusion, our analysis demonstrates that public opinion and interest groups are both factors affecting policy priorities in the American states. One interpretation of these results would be optimism about popular influence over government. But, we believe some caution is still necessary. On the one hand, we suspect that policy priorities constitute the main point of access for the mass public, at least under most circumstances. On the other hand, lobbying activities permeate the entire governmental process. Therefore, further research is definitely 
necessary to disentangle the roles of public opinion and interest groups and to assess their respective net effects on policymaking at the state level. 


\section{NOTES}

1. The full policy priorities dataset covers the time period from 1982 through 2000 . The scaling approach that we use to estimate the parameters of the spatial proximity model provides separate sets of policy and state points for each year. The point locations are estimated separately within each year. But the estimates are obtained from an iterative process that uses the preceding year's estimates as a starting point. This is fully consistent with the substantive nature of state decisionmaking processes, wherein the previous year's budget is used as the baseline for spending allocations in any given year.

2. The actual yearly scale values for policies and states are available from the authors.

3. Note that this coding is reversed from the original scheme. Wright and his colleagues subtracted the proportion of Republicans (or conservatives) from the proportion of Democrats (or liberals) within each state. We reversed this simply to make the correlations with the policy priorities variable positive, rather than negative.

4. Once again, this is a reversal of the original coding used by Berry and his colleagues, which gives higher scores to more liberal states.

5. We also tried an alternative specification, by including the Wright, Erikson, McIver electorate ideology measure in the equation (both along with, and as a replacement for, the Berry et al. variable). However, after controlling for the other independent variables, it is completely unrelated to policy priorities. Therefore, we dropped it from the model that we report here. 


\section{REFERENCES}

Bachrach, Peter, and Morton Baratz. 1962. "Two Faces of Power.” American Political Science Review 56: 947-952.

Barrilleaux, Charles, Thomas Holbrook, and Laura Langer. 2002. "Electoral Competition, Legislative Balance, And American State Welfare Policy." American Journal of Political Science 46: 415-427.

Baumgartner, Frank R., and Bryan D. Jones. 1993. Agendas and Instability in American Politics. Chicago: University of Chicago Press.

Berry, William D., Evan J. Ringquist, Richard C. Fording, and Russell L. Hanson. 1998. "Measuring Citizen and Government Ideology in the American States, 1960-93." American Journal of Political Science 42(1): 327-348.

Burstein, Paul. 2003. "The Impact of Public Opinion on Public Policy: A Review and an Agenda." Political Research Quarterly 56: 29-40.

Campbell, Angus, Philip Converse, Warren Miller, and Donald Stokes. 1960. The American Voter. New York: Wiley.

Carmines, E. G., and Stimson, James A. 1980. "The Two Faces of Issue Voting.” American Political Science Review 74: 78-91.

Coombs, Clyde H. (1964) A Theory of Data (New York: John Wiley).

Cox, Trevor, and Michael A.A. Cox. 2000. Multidimensional Scaling, $2^{\text {nd }}$ ed. New York: Chapman and Hall/CRC.

Dahl, Robert A. 1961. Who Governs? New Haven: Yale University Press.

Dawson, Richard E., and James A Robinson. 1963. "Inter-Party Competition, Economic Variables, and Welfare Policies in the American States." Journal of Politics 25(2): $265-$ 289.

Dye, Thomas. 1966. Politics, Economics, and the Public: Policy Outcomes in the American States. Chicago: Rand McNally.

Elazar, Daniel. 1966. American Federalism: A View from the States. New York: Thomas Y. Crowell.

Elazar, Daniel. 1984. American Federalism: A View from the States. New York: Harper and Row. 
Erikson, Robert S., Gerald C. Wright, Jr., and John P. McIver. 1989. "Political Parties, Public Opinion, and State Policy in the United States." American Political Science Review 83(3): 729-750.

Erikson, Robert S., Gerald C. Wright, Jr., and John P. McIver. 1993. Statehouse Democracy: Public Opinion and Policy in the American States. Cambridge University Press.

Eyestone, Robert. 1977. “Confusion, Diffusion, and Innovation.” American Political Science Review 71: 441-447.

Garand, James C. 1985. "Partisan Change and Shifting Expenditure Priorities in the American States, 1945-1978." American Politics Quarterly 14(4): 355-391.

Garand, James C. 1988. "Explaining Government Growth in the U.S. States.” American Political Science Review 82(3): 837-849.

Garand, James C., and Rebecca M. Hendrick. 1991. "Expenditure Tradeoffs in the American States: A Longitudinal Test, 1948-1984.” Western Political Quarterly 44(4): 915-940.

Garreau, Joel . 1981. The Nine Nations of North America. Boston: Houghton Mifflin Company.

Gray, Virginia. 1973. "Innovation in the States: A Diffusion Study." American Political Science Review 67: 1174-1185.

Gray, Virginia. 1999. "The Socioeconomic and Political Context of States." In Politics in the American States: A Comparative Analysis, eds. Virginia Gray and Herbert Jacob. 7th ed. Washington, DC: Congressional Quarterly.

Gray, Virginia, and David Lowery. 1988. "Interest Group Politics and Economic Growth in the U.S. States.” American Political Science Review 82(1): 109-31.

Gray, Virginia, and David Lowery. 1996. The Population Ecology of Interest Representation: Lobbying Communities in the American States. Ann Arbor, MI: The University of Michigan Press.

Gray, Virginia, David Lowery, Matthew Fellowes, and Andrew McAttee. 2004. "Public Opinion, Public Policy, and Organized Interests in the American States." Political Research Quarterly. forthcoming.

Hanson, Russell L. 1983. "The 'Content' of Welfare Policy: The States and Aid to Families with Dependent Children.” Journal of Politics 45(3): 771-785.

Heclo, Hugh. 1978. "Issue Networks and the Executive Establishment." In Anthony King, ed. The New American Political System. Washington, DC: American Enterprise Institute. 
Hill, Jim Q., Jan Leighley, and Angela Hinton-Anderson. 1995. "Lower-Class Mobilization and Policy Linkage in the U.S. States.” American Journal of Political Science 39:75-86.

Hofferbert, Richard I. 1974. The Study of Public Policy. New York: The Bobbs-Merrill Company, Inc.

Jacoby, William G. 1995. "The Structure of Ideological Thinking in the American Electorate." American Journal of Political Science 39: 314-335.

Jacoby, William G. (1997) Statistical Graphics for Univariate and Bivariate Data. Beverly Hills, CA: Sage Publications.

Jacoby, William G. 2002. "Core Values and Political Attitudes.” In Understanding Public Opinion. ed. Barbara Norrander and Clyde Wilcox, $2^{\text {nd }}$. ed. Washington, DC: Congressional Quarterly Press, pp. 177-202.

Jacoby, William G., and Saundra K. Schneider. 2001. "Variability in State Policy Priorities: An Empirical Analysis.” Journal of Politics 63: 544-548.

Key, V.O., Jr. 1949. Southern Politics. New York: Vintage Books.

Kingdon, John W. 1995. Agendas, Alternatives, and Public Policies, $2^{\text {nd }}$ ed., Boston: Little, Brown, and Company.

Klingman, David, and William W. Lammers. 1984. "The 'General Policy Liberalism' Factor in American State Politics.” American Journal of Political Science 28(3): 598-610.

Lascher, Edward L., Jr., Michael G. Hagen, and Steven A. Rochlin. (1996) “Gun Behind the Door? Ballot Initiatives, State Policies and Public Opinion.” The Journal of Politics 58: 760-775.

Lewis, Dan A., and Shadd Maruna. 1999. "The Politics of Education.” In Politics in the American States. eds. Virginia Gray, Russell L. Hanson, and Herbert Jacob. $7^{\text {th }}$ ed. Washington, DC: Congressional Quarterly Press.

Lowery, David, Virginia Gray, and Gregory Hager. 1989. "Public Opinion and Policy Change in the American States." American Politics Quarterly 17: 3-31.

Lowi, Theodore. 1964. "American Business, Public Policy, Case Studies and Political Theory." World Politics 16: 677-715.

Peterson, Paul E. 1996. The Price of Federalism. Washington, DC: Brookings Institution.

Poole, Keith T. (1981) "Dimensions of Interest Group Evaluations of the U.S. Senate, 19691978." American Journal of Political Science 25: 49-67. 
Poole, Keith J. (1984) "Least Squares, Metric, Unidimensional Unfolding." Psychometrika 49: 311-323.

Raimondo, Henry J. 1996. "State Budgeting: Problems, Choices, and Money." In The State of The States, ed. Carl E. Van Horn. 3rd ed. Washington, DC: Congressional Quarterly Press.

Ringquist, Evan. J. Environmental Protection at the State Level. Armonk, New York: M.E. Sharpe.

Ringquist, Evan J., and James C. Garand. 1999. "Policy Change in the American States," In American State and Local Politics: Directions for the $21^{\text {st }}$ Century, eds. Ronald E. Weber and Paul Brace. New York: Chatham House.

Rom, Mark. 1999. "Transforming State Health and Welfare Programs." In Politics in the American States. eds. Virginia Gray, Russell Hanson, and Herbert Jacob, $7^{\text {th }}$ ed. Washington, DC: Congressional Quarterly Press.

Schattschneider, E. E. (1960) The Semisovereign People. New York: Holt, Rhinehart, and Winston.

Sharkansky, Ira. 1967. "Government Expenditures and Public Policies in the American States." American Political Science Review 61: 1066-1077

Sharkansky, Ira. 1969. “The Utility of Elazar's Political Culture.” Polity 2: 66-83.

Sharkansky, Ira, and Richard I. Hofferbert. 1969. "Dimensions of State Politics, Economics, and Public Policy." American Political Science Review 63(3): 867-879.

Truman, David. 1951. The Governmental Process. New York: Alfred A. Knopf.

Walker, Jack . 1969. "Innovation in the States: A Diffusion Study.” American Political Science Review 67: 1174-1185.

Wright, Gerald C., Robert S. Erikson, and John P. Mciver. 1985. "Measuring State Partisanship and Ideology with Survey Data." Journal of Politics 47: 469-489.

Wright, Gerald C., Robert S. Erikson, and John P. McIver. 1987. "Public Opinion and Policy Liberalism in the American States." American Journal of Political Science 31(3): 9801007.

Zaller, John R. 1992. The Nature and Origins of Mass Opinion. New York: Cambridge University Press. 
Table 1: The impact of public opinion, interest groups, and region on state policy priorities.

\begin{tabular}{|c|c|c|}
\hline & $\begin{array}{c}\text { Prais-Winston } \\
\text { Coefficient Estimates }\end{array}$ & $\begin{array}{l}\text { Panel-Corrected } \\
\text { Standard Errors }\end{array}$ \\
\hline \multicolumn{3}{|l|}{ Public Opinion: } \\
\hline $\begin{array}{c}\text { Electorate } \\
\text { partisanship }\end{array}$ & $8.510^{*}$ & 5.132 \\
\hline $\begin{array}{l}\text { Citizen } \\
\text { ideology }\end{array}$ & 0.136 & 0.126 \\
\hline \multicolumn{3}{|l|}{ Interest Groups: } \\
\hline $\begin{array}{r}\text { Groups working } \\
\text { on collective goods }\end{array}$ & $1.161^{*}$ & 0.244 \\
\hline $\begin{array}{l}\text { Groups working on } \\
\text { particularized benefits }\end{array}$ & $-0.245^{*}$ & 0.057 \\
\hline \multicolumn{3}{|l|}{ Region: } \\
\hline $\begin{array}{r}\text { Northeastern } \\
\text { states }\end{array}$ & $-28.136^{*}$ & 4.921 \\
\hline $\begin{array}{r}\text { Southern } \\
\text { states }\end{array}$ & $-4.905^{*}$ & 1.757 \\
\hline $\begin{array}{r}\text { Western } \\
\text { states }\end{array}$ & $-5.929 *$ & 0.952 \\
\hline Intercept & 50.058 & \\
\hline $\mathrm{R}^{2}$ & 0.776 & \\
\hline Rho (autoregression) & 0.679 & \\
\hline
\end{tabular}

* Coefficient is statistically different from zero at the 0.05 level. One-sided tests are used for the public opinion and interest group variables. Two-sided tests are used for the region variables.

Note: The dependent variable consists of the policy priority score for each state, for 1998, 1999, and 2000. The public opinion and interest group variables are lagged one year. The total number of observations is 150 . 
Table 2: The impact of public opinion and region on the proportion of interest groups within a state working on collective goods and particularized benefits.

\begin{tabular}{|c|c|c|}
\hline & \multicolumn{2}{|c|}{ Dependent Variable } \\
\hline & $\begin{array}{l}\text { Collective } \\
\text { Goods }\end{array}$ & $\begin{array}{c}\text { Particularized } \\
\text { Benefits }\end{array}$ \\
\hline \multicolumn{3}{|l|}{ Public Opinion: } \\
\hline $\begin{array}{r}\text { Electorate } \\
\text { Partisanship }\end{array}$ & $\begin{array}{c}2.810^{*} \\
(1.629)\end{array}$ & $\begin{array}{l}-1.726 \\
(1.648)\end{array}$ \\
\hline $\begin{array}{r}\text { Citizen } \\
\text { Ideology }\end{array}$ & $\begin{array}{c}0.102 * \\
(0.028)\end{array}$ & $\begin{array}{l}-0.002 \\
(0.011)\end{array}$ \\
\hline \multicolumn{3}{|l|}{ Region: } \\
\hline $\begin{array}{r}\text { Northeastern } \\
\text { States }\end{array}$ & $\begin{array}{l}-0.432 \\
(0.662)\end{array}$ & $\begin{array}{r}0.197 \\
(0.113)\end{array}$ \\
\hline $\begin{array}{r}\text { Southern } \\
\text { States }\end{array}$ & $\begin{array}{l}-2.351 * \\
(0.179)\end{array}$ & $\begin{array}{c}0.817^{*} \\
(0.272)\end{array}$ \\
\hline $\begin{array}{r}\text { Western } \\
\text { States }\end{array}$ & $\begin{array}{c}4.086^{*} \\
(0.218)\end{array}$ & $\begin{array}{l}-3.073 * \\
(0.076)\end{array}$ \\
\hline Intercept & 31.587 & 33.233 \\
\hline $\mathrm{R}^{2}$ & 0.919 & 0.967 \\
\hline Rho (autoregression) & 0.745 & 0.804 \\
\hline
\end{tabular}

* Coefficient is statistically different from zero, 0.05 level. One-sided tests are used for the public opinion variables, and two-sided tests for the region variables.

Note: The dependent variable for each regression consists of the proportion of interest groups within a state (i.e., groups registered to lobby in that state) working for either collective goods or particularized benefits. Data cover the years 1997-1999, so the total number of observations is 150. 
Figure 1: Dot plot of policy scores from spatial proximity model of state expenditures, 19982000.

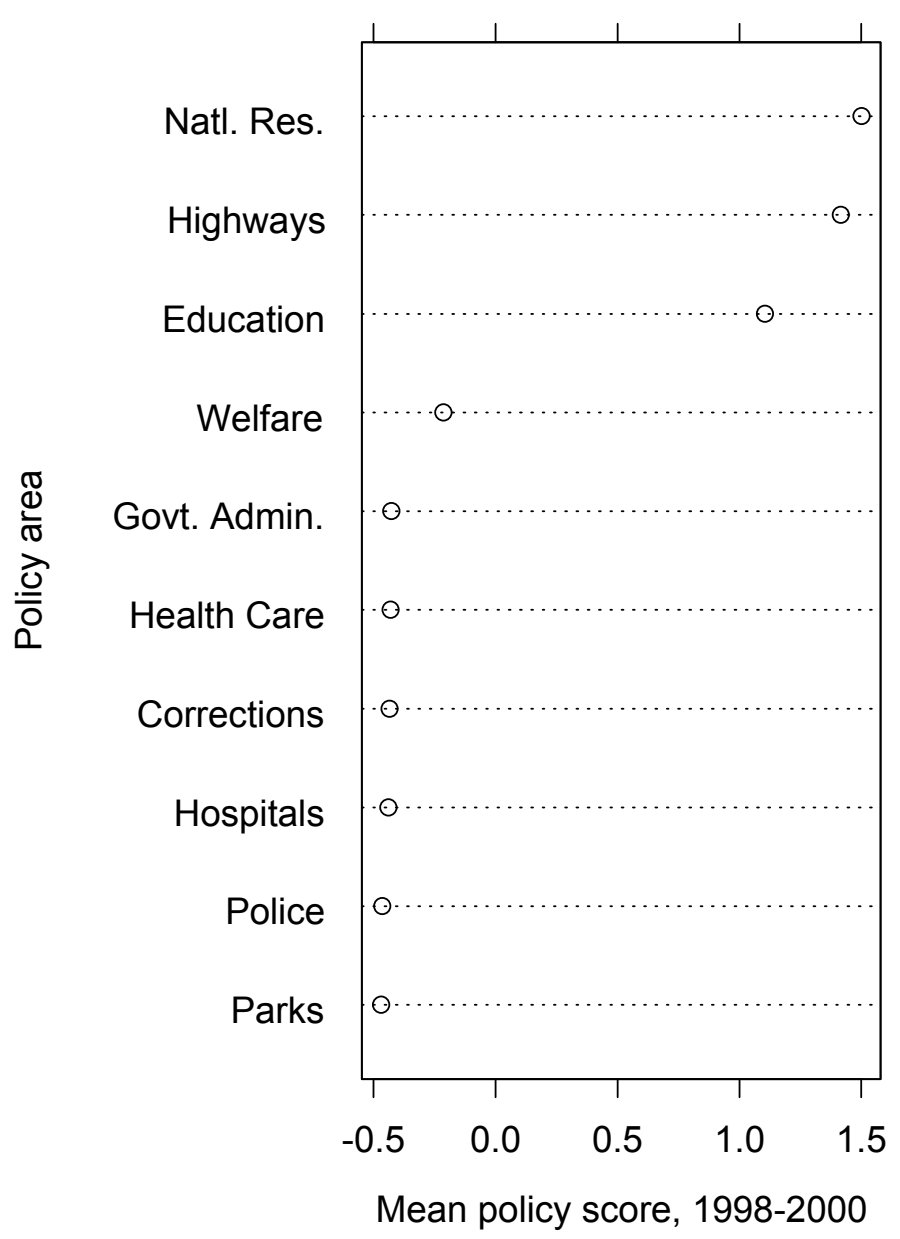

Note: Each plotted point is the mean coordinate value for that policy, calculated across the three years from 1998 through 2000. 
Figure 2: Dot plot of state scores from spatial proximity model of state expenditures, 1998-2000.

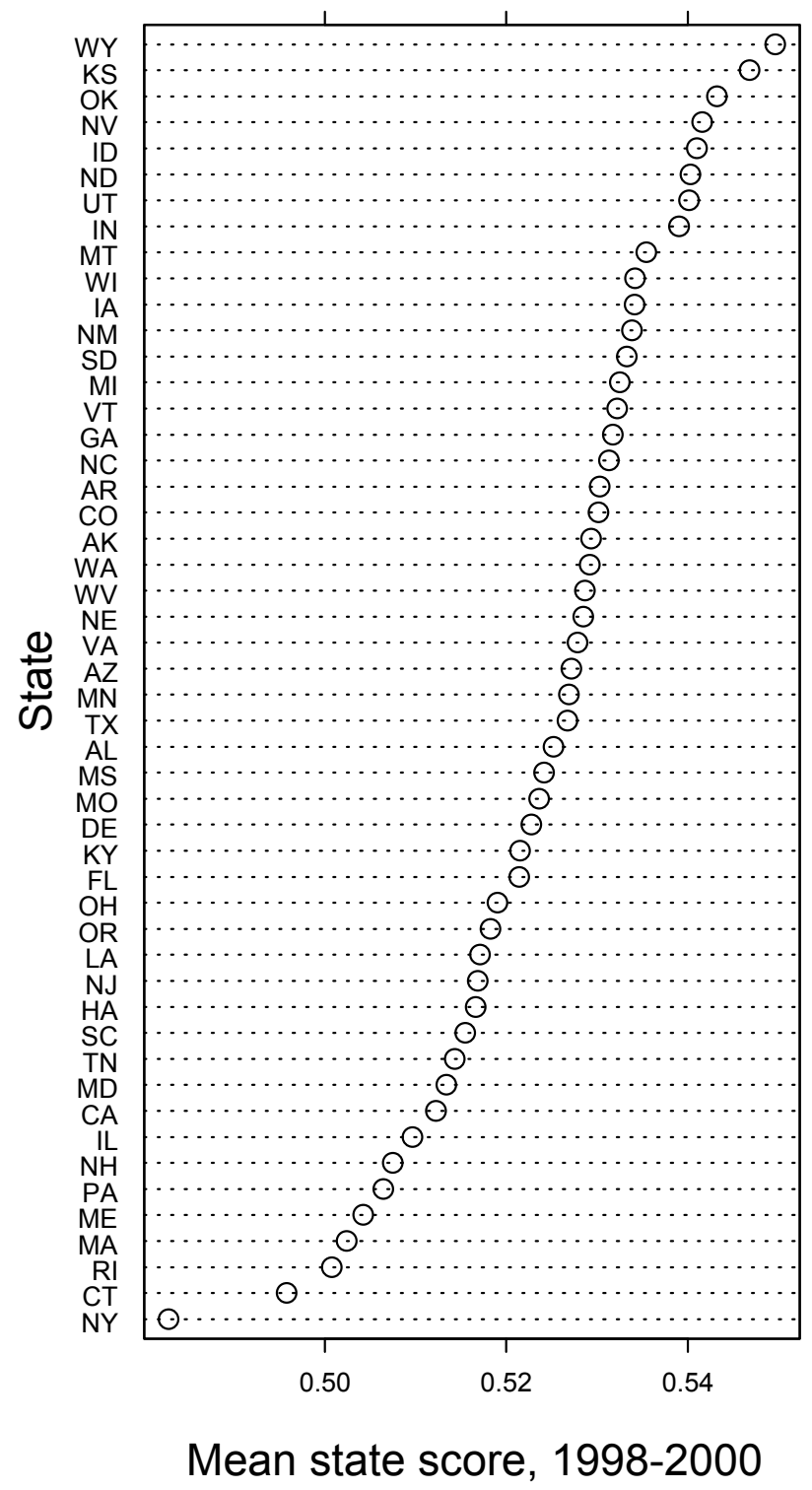

Note: Each plotted point is the mean of the coordinate values for that state, calculated across the three years from 1998 through 2000. 
Figure 3: Distribution of 1998-2000 state policy priorities, by political culture.

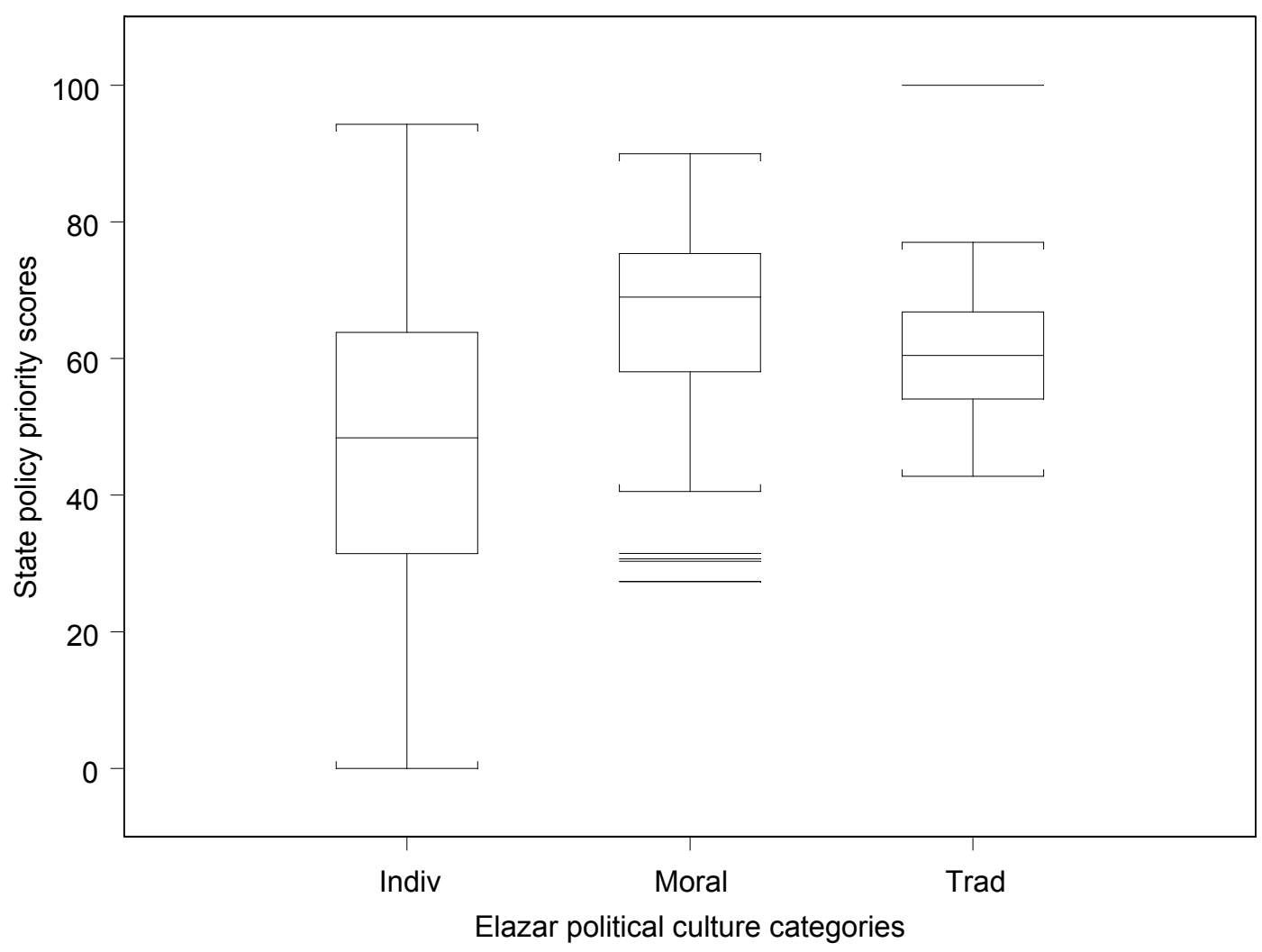

Data sources: State policy priority scores are obtained from the unfolding analysis of 1998-2000 state policy expenditures. States are placed in political culture categories using the scheme developed by Elazar (1984). 
Figure 4: The relationship between state policy priorities and Sharkansky's political culture scores.

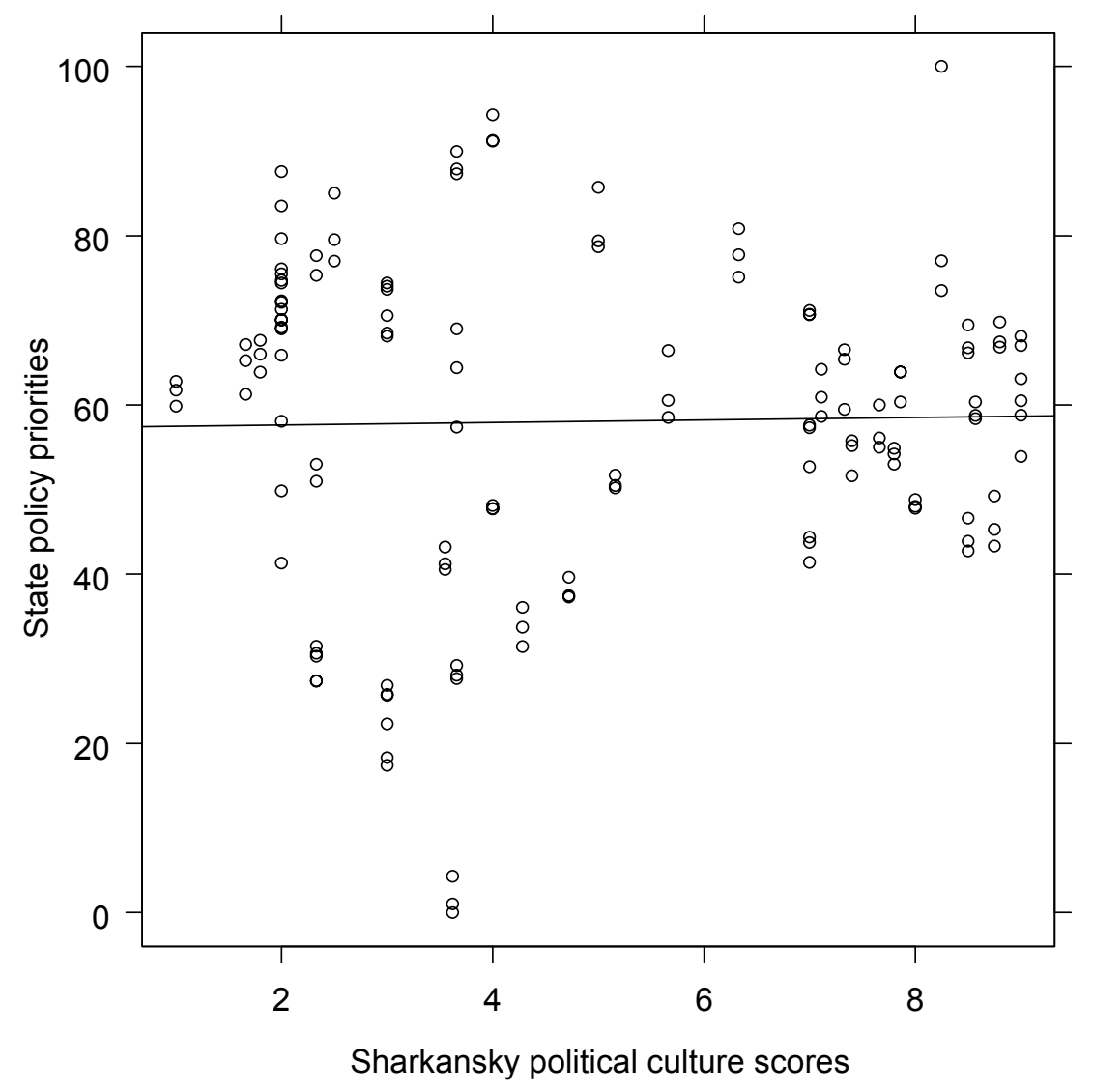

Data sources: State policy priority scores are obtained from the unfolding analysis of 1998-2000 state policy expenditures. States political culture scores are obtained from Sharkansky (1967). 
Figure 5: Distribution of 1998-2000 state policy priorities, by region.

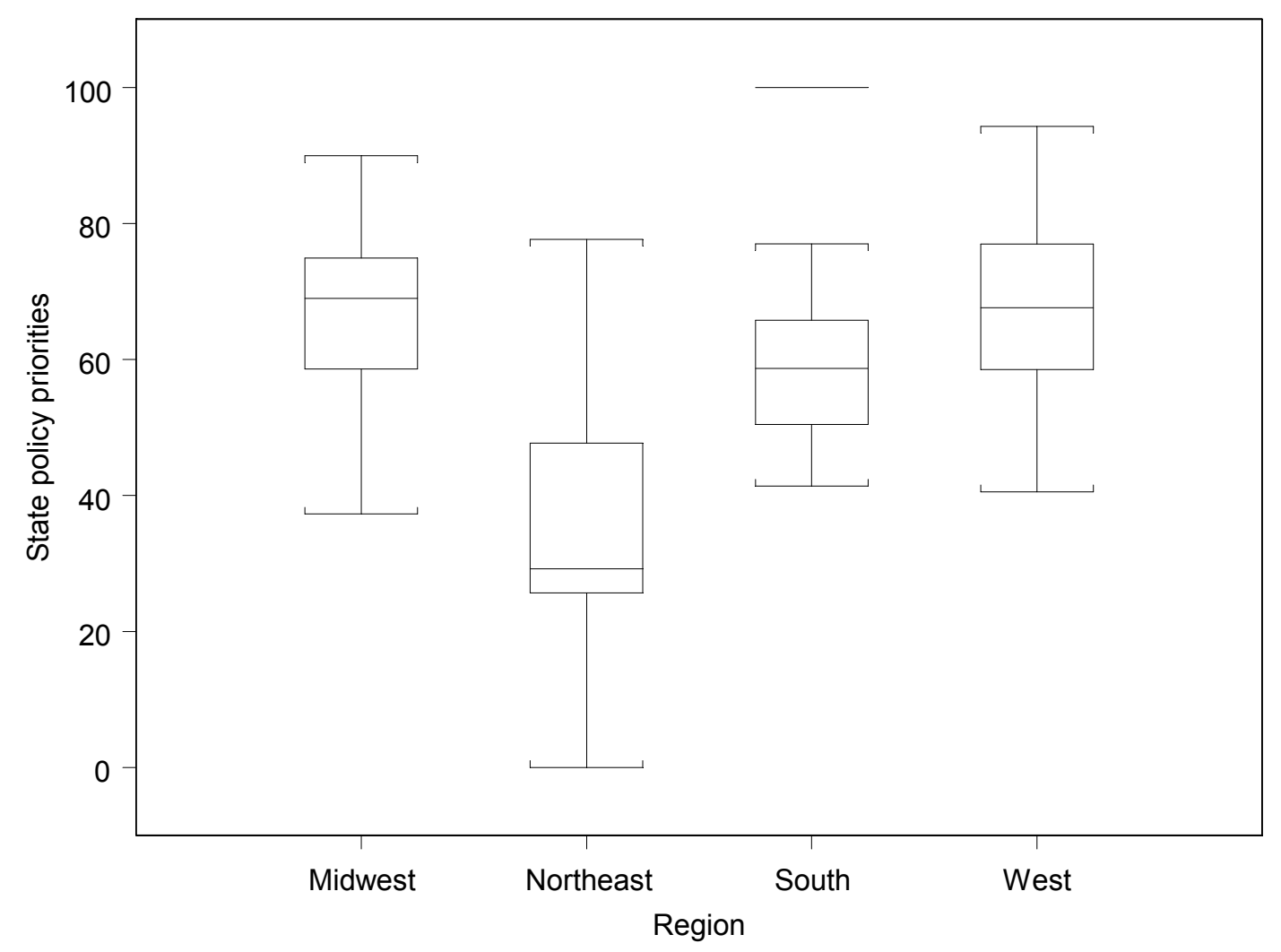

Data sources: State policy priority scores are obtained from the unfolding analysis of 1998-2000 state policy expenditures. Region categories are identical to those used in Erikson, Wright, McIver (1993). 
Figure 6: The relationship between state policy priorities and state electorate partisanship.

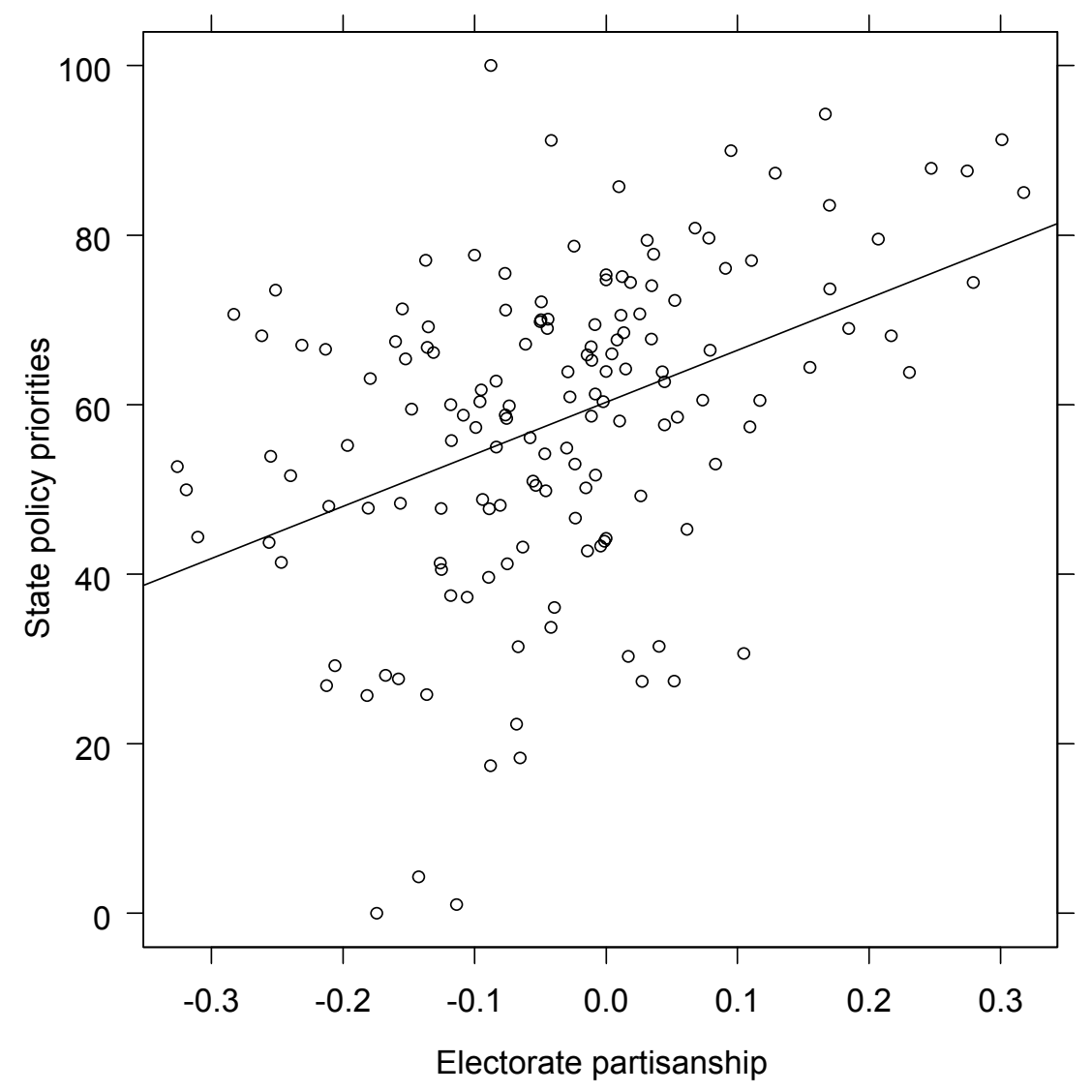

Data sources: State policy priority scores are obtained from the unfolding analysis of 1998-2000 state policy expenditures. State electorate partisanship scores are downloaded from Gerald Wright's web site (http://php.indiana.edu/ wright1/). 
Figure 7: The relationship between state policy priorities and state electorate ideology.

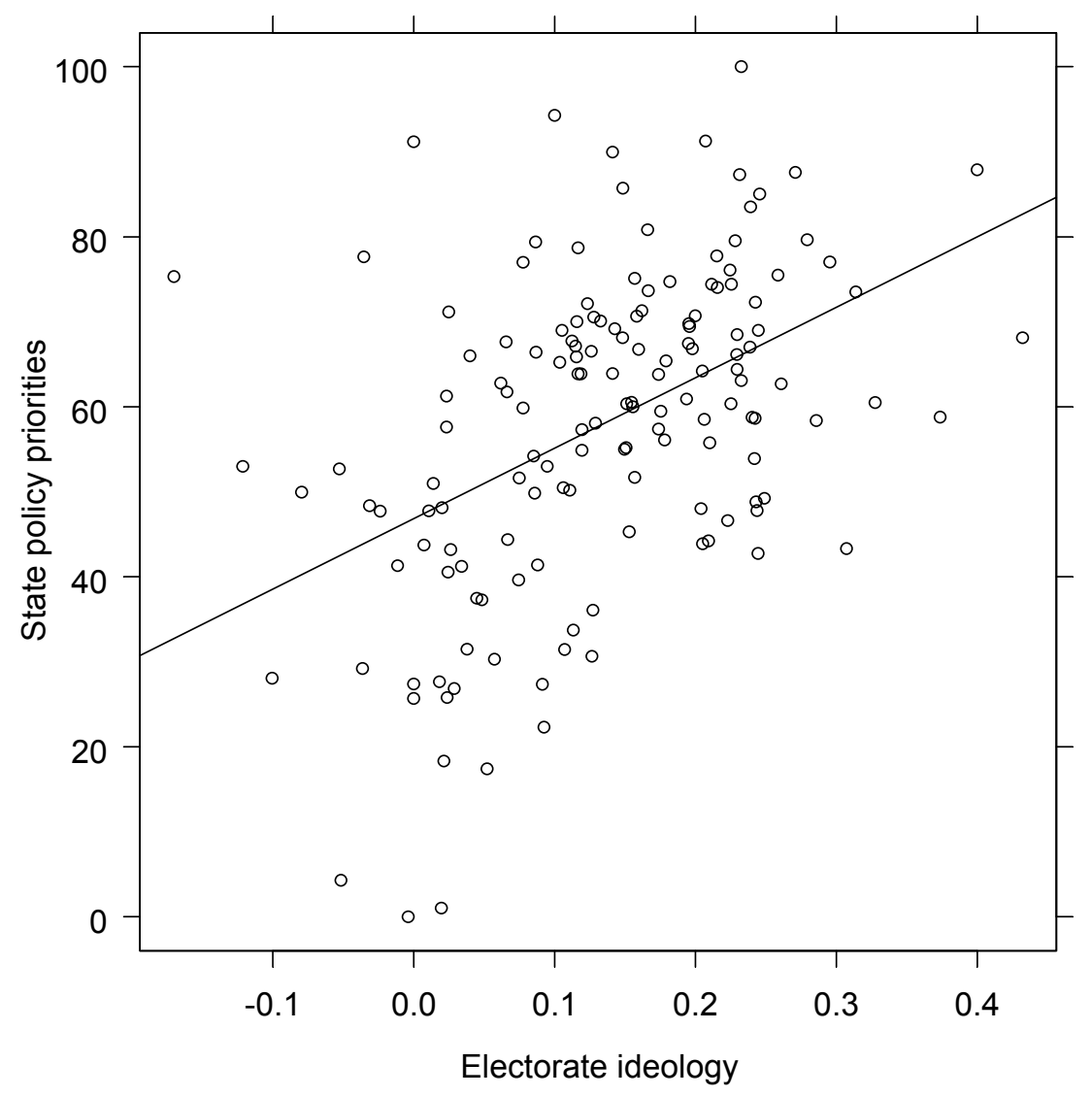

Data sources: State policy priority scores are obtained from the unfolding analysis of 1998-2000 state policy expenditures. State electorate ideology scores are downloaded from Gerald Wright's web site (http://php.indiana.edu/ wright1/). 
Figure 8: The relationship between state policy priorities and state citizen ideology.

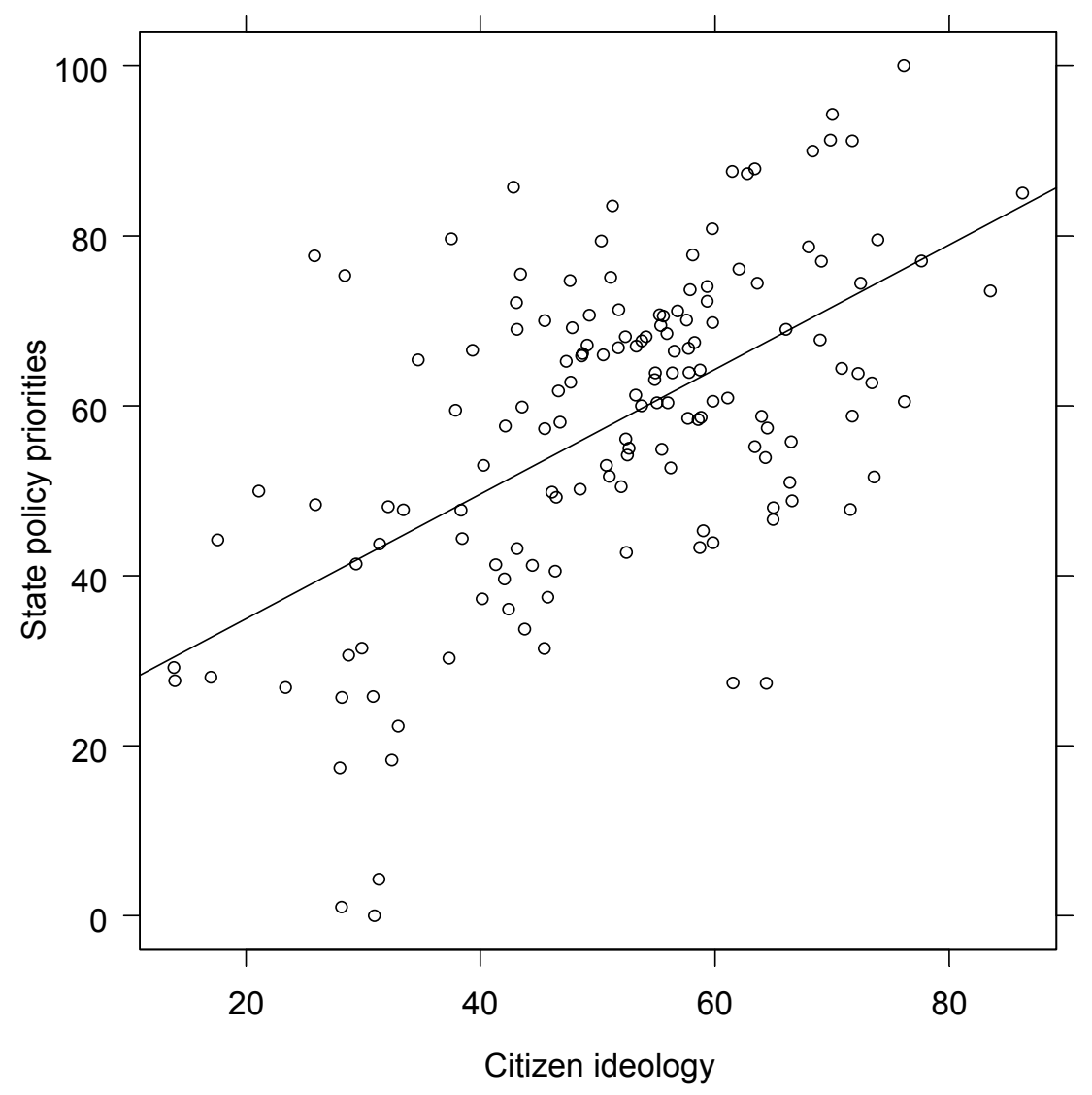

Data sources: State policy priority scores are obtained from the unfolding analysis of 1998-2000 state policy expenditures. State citizen ideology scores are those defined by Berry, Ringguist, Fording, Hanson (1998). The values for 1997-1999 used here are obtained from ICPSR (Study Number 1208). 
Figure 9: The relationship between state policy priorities and the proportion of interest groups within a state working toward the attainment of collective goods.

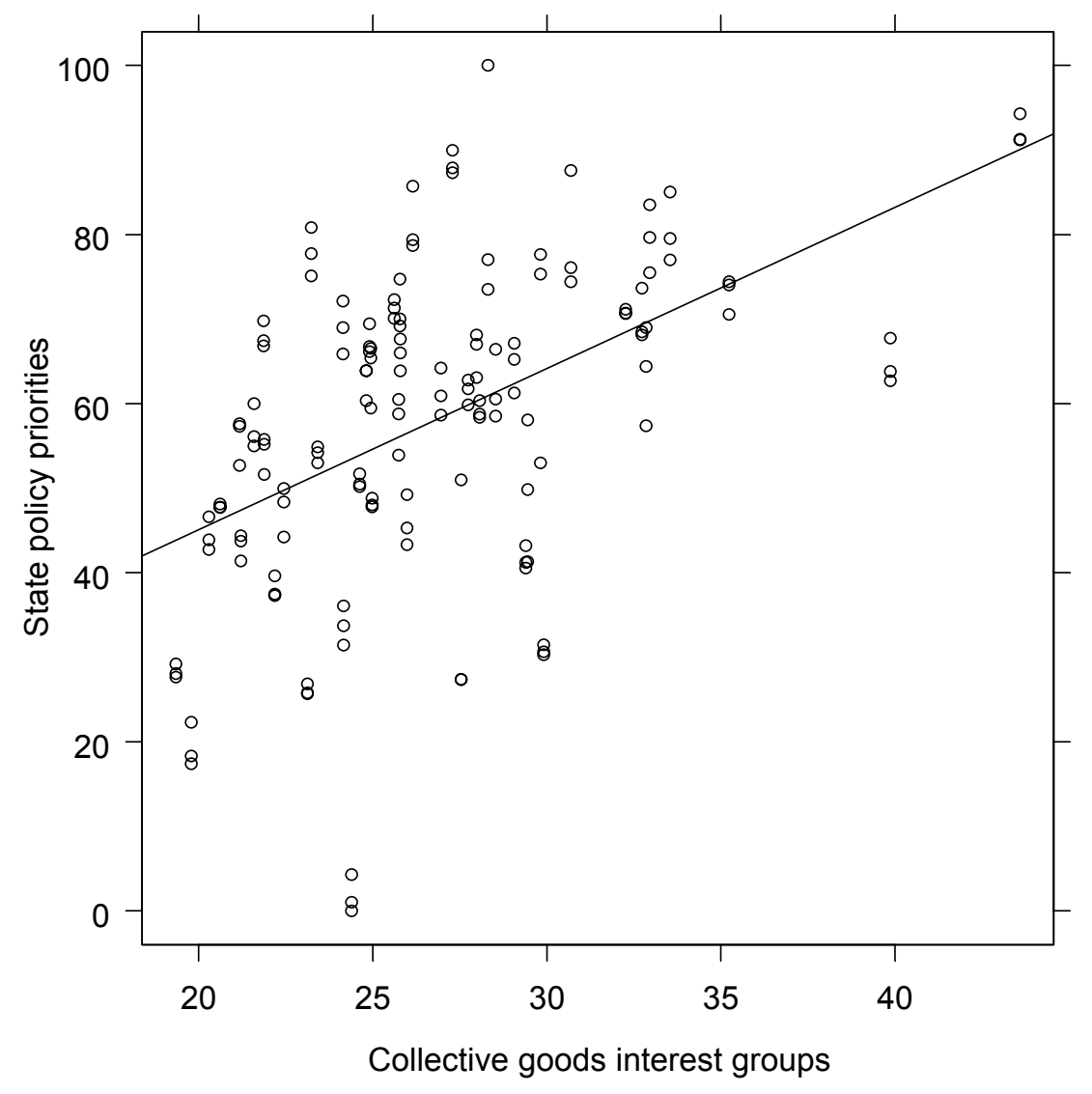

Data sources: State policy priority scores are obtained from the unfolding analysis of 1998-2000 state policy expenditures. Interest group data are provided by David Lowery and Virginia Gray. 
Figure 10: The relationship between state policy priorities and the proportion of interest groups within a state working for the attainment of particularized benefits

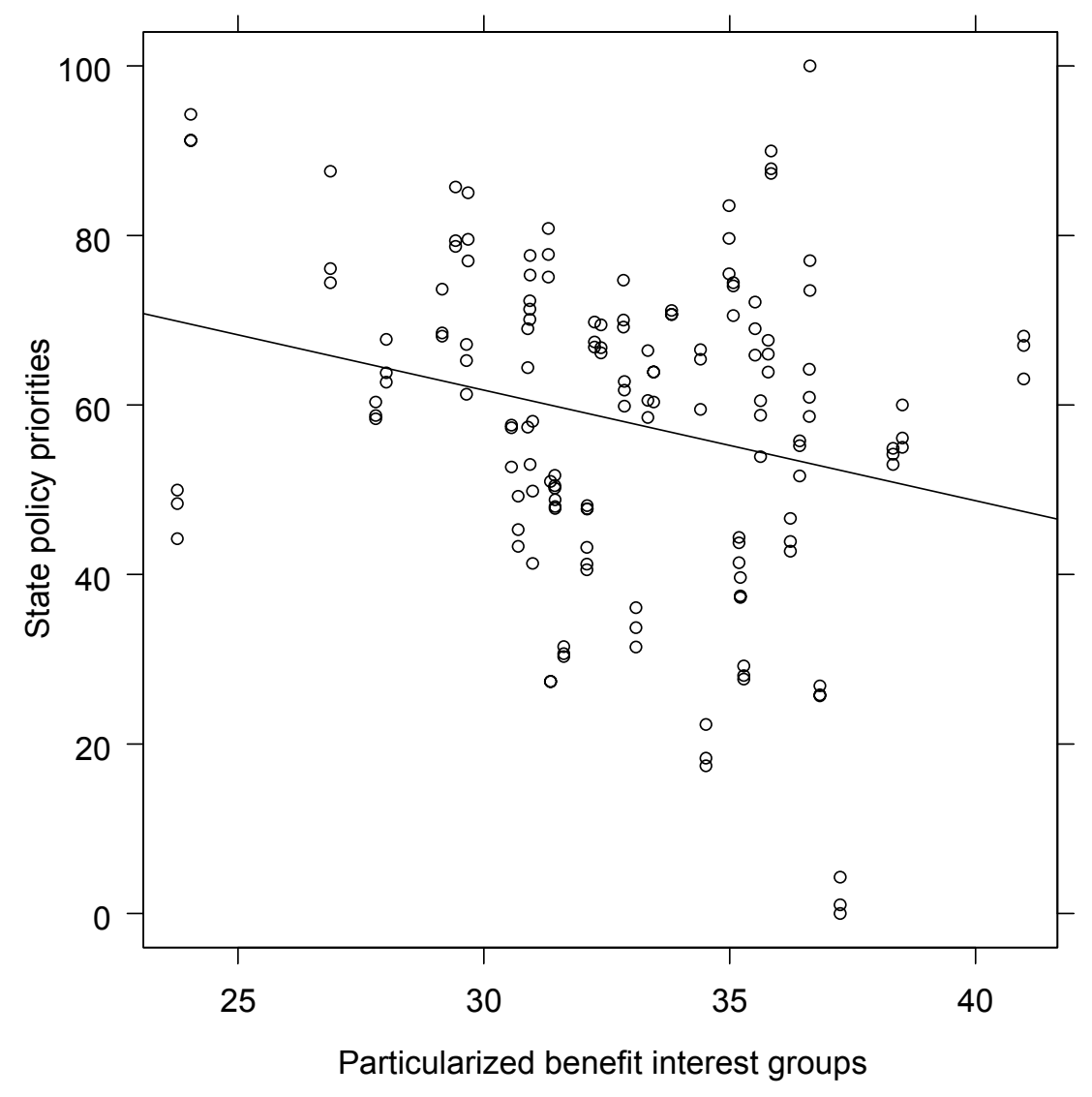

Data sources: State policy priority scores are obtained from the unfolding analysis of 1998-2000 state policy expenditures. Interest group data are provided by David Lowery and Virginia Gray. 